\title{
Bullous fixed drug eruption secondary to dietary supplement
}

\section{Rhizlane Chaoui, Zakia Douhi, Selma El Kadiri, Sara Oukarfi, Sara Elloudi, Hanane Baybay, Fatima Zahra Mernissi}

Department of Dermatology, CHU Hassan II, Fez, Morocco

Corresponding author: Dr. Rhizlane Chaoui, E-mail: chaoui.rhizlane@gmail.com

\begin{abstract}
Fixed drug eruption (FDE) is the most common cutaneous adverse drug reaction..It is characterized by solitary or multiple oval or round lesions that may affect any part of the body. D-Stress is a dietary supplement against stress. It contains $120 \mathrm{mg}$ of magnesium element as well as Taurine, Arginine and B vitamins, acting synergistically to physiologically adapt the body to any stress or fatigue situation. We report a rare case of 16 years old female patient developed generalized bullous FDE after administration of D-Stress. To our knowledge, this is the first case reported in the literature of FDE secondary to dietary supplement use.
\end{abstract}

Key words: Fixed drug eruption; Dietary supplement; Stress

\section{INTRODUCTION}

Fixed drug eruption (FDE) is a cutaneous adverse drug reaction (CADR) due to type IV or delayed cell mediated hypersensitivity [1]. It is characterized by solitary or multiple oval or round lesions that may affect any part of the body. These lesions are commonly developed in trunk, lips, hands, and genital mucosa and presented as an erythematous patch which occurs after administration of an offending drug within hours and heals with residual hyperpigmentation and may recur on the same sites upon read ministration of the same causative agent.

Antimicrobial, anti-inflammatory, and anti-convulsive agents are the most common causative drugs associated with FDE.

We report in our knowledge the first case of fixed bullous drug eruption secondary to dietary supplement.

\section{CASE REPORT}

A 16-year-old female with no particular medical history. She consulted the emergency department for a hysteria attack putted under D STRESS, 3 days later she showed erythematous itchy lesions on the trunk, back and thighs. She had no history of allergic disease or allergic reactions to drugs.

Dermatologic examination revealed erythematous plaques, partly disappearing at the vitropression of variable size, well defined with irregular contours sitting in chin, the trunk, back and the lower limbs (Figs. la - ld), with central blistering of those sitting in thigh and abdomen (Figs. 2a and 2b). The rest of the physical examination did not reveal any abnormalities.

Initially, we evoque fixed drug eruption, purpuric capillaries.

After performing biopsy, the lesion was diagnosed as fixed drug eruption.

A pharmacovigilance investigation was conducted, and D stress was confirmed as the agent responsible for the bullous fixed drug eruption (FDE) in our patient.

Our patient was put on dermocorticoid with degression. The evolution was marked by a clear improvement of

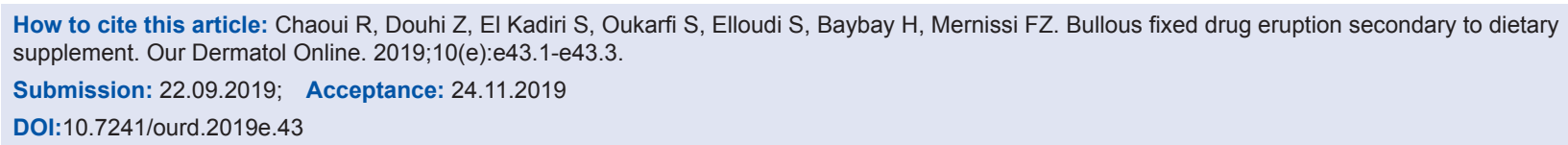




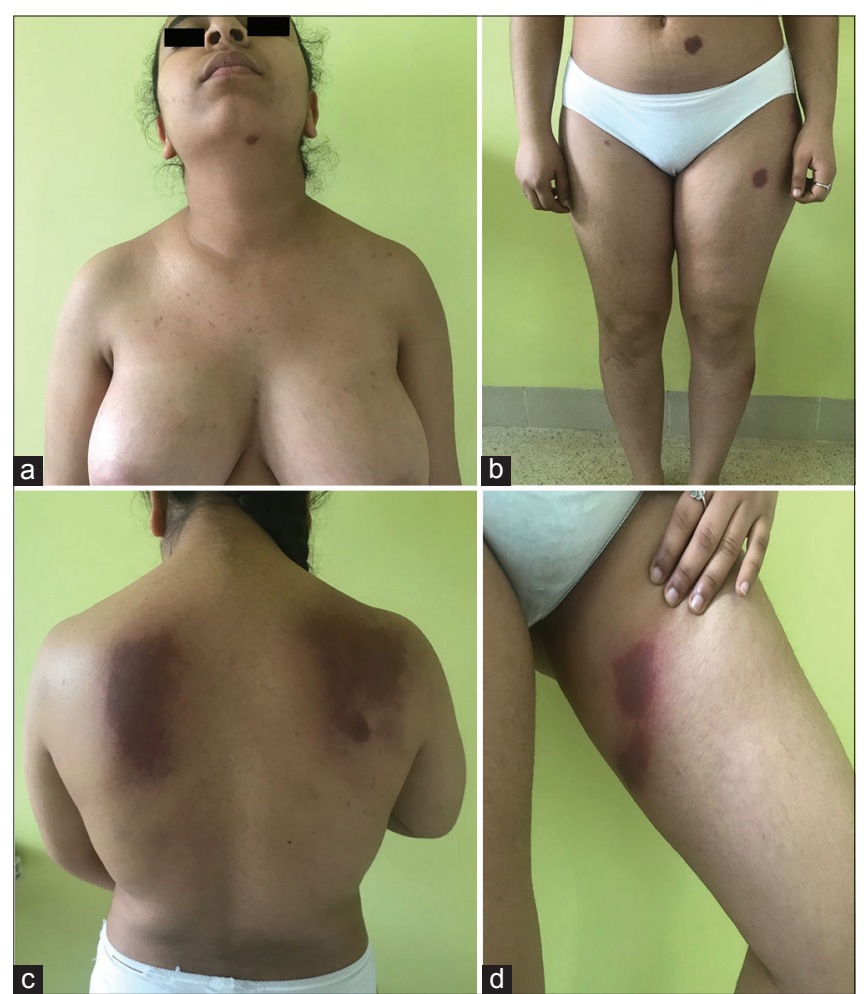

Figure 1: (a-d) Erythematous plaques, well defined with irregular contours sitting in chin, the trunk, back and the lower limbs.

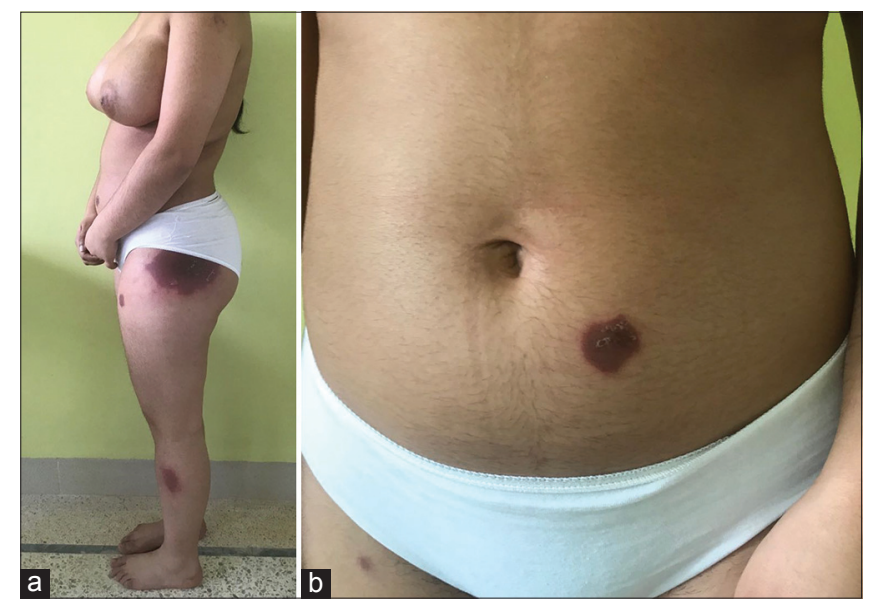

Figure 2: $(a$ and $b)$ Central blistering of the lesions sitting in thigh and abdomen.

the lesions with a residual pigmentation after 1 month of treatment (Figs. 3a and 3b).

\section{DISCUSSION}

FDE is one of the most prevalent cutaneous drug induced reactions, and classically presents as a distinctly bordered erythematous lesion that periodically recurs at the same site after administration of a causative drug [1].

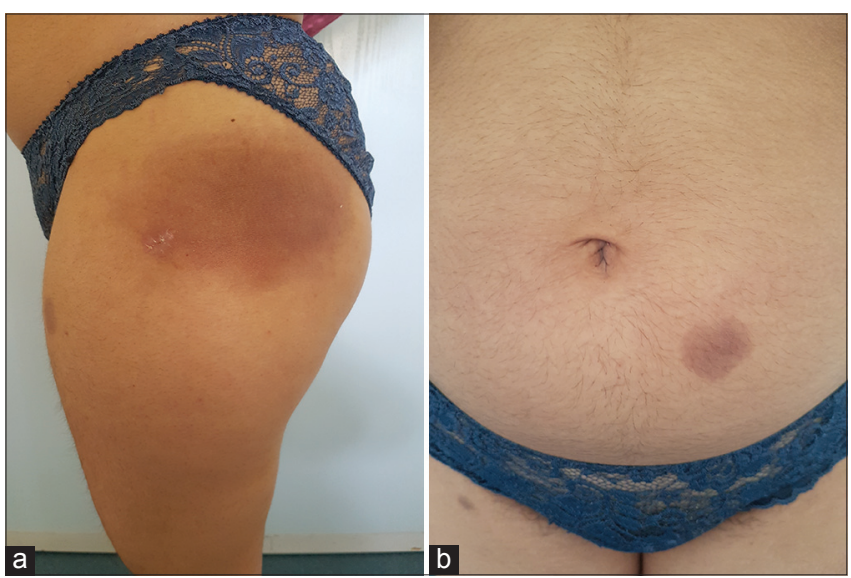

Figure 3: $(a$ and $b)$ Pigmentation after 1 month of treatment.

The drugs most commonly associated with FDE are antibiotics, analgesics, and anticonvulsants [2].

FDE has multiple variants, including generalized, linear, bullous, urticarial, pigmenting, nonpigmenting, wandering, eczematous, psoriasiform, erythema dyschromicum perstans like vulvitis and oral FDE [3]. The bullous form remain rare.

Till now pathogenesis of FDE is unknown but cell-mediated immunity, certain serum factors, and antibodies are some of the causative factors. Intraepidermal CD $8+\mathrm{T}$ cells are thought to be responsible for cutaneous manifestations in FDE, producing large amounts of IFN-g. After drug reexposure, cutaneous lesions may occur because of prolonged expression of intercellular adhesion molecule-l in basal keratinocytes by participation of CD8+ effector/memory T cells [4].

D-Stress is a dietary supplement against stress. It contains $120 \mathrm{mg}$ of magnesium element as well as Taurine, Arginine and B vitamins, acting synergistically to physiologically adapt the body to any stress or fatiguew situation.

FDE is a clinical diagnosis and histological findings are usually supportive.

The initial treatment of FDE is discontinuation of the causative agent, after which lesions typically improve, leaving only hyperpigmented changes on previously affected areas [4].

\section{CONCLUSION}

To our knowledge, this is the first case reported in the literature of FDE secondary to dietary supplement use. 
The crucial elements to confirm the diagnosis are the patient's medical history and the clinical presentation of the lesions.

\section{Consent}

The examination of the patient was conducted according to the Declaration of Helsinki principles.

The authors certify that they have obtained all appropriate patient consent forms. In the form the patient(s) has/have given his/her/their consent for his/her/their images and other clinical information to be reported in the journal. The patients understand that their names and initials will not be published and due efforts will be made to conceal their identity, but anonymity cannot be guaranteed.

\section{REFERENCES}

1. Ratinder J, Dinesh P, Deepa C. Fixed drug eruption due to levocetirizine. J Pharmacol Pharmacother. 2016;7:109-11.

2. Flowers H, Brodell R, Brents M, Wyatt JP. Fixed drug eruptions: presentation, diagnosis, and management. South Med J. 2014;107:724-5.

3. Özkaya E, Oral mucosal fixed drug eruption: characteristics and differential diagnosis, J Am Acad Dermatol. 2013;69:e51-8.

4. Hoetzenecker W, Nägeli M, Mehra ET, Jensen AN, Saulite I, Schmid-Grendelmeier P, et al. Adverse cutaneous drug eruptions: current understanding. Semin Immunopathol. 2016;38:75-86.

Copyright by Rhizlane Chaoui, et al. This is an open access article distributed under the terms of the Creative Commons Attribution License, which permits unrestricted use, distribution, and reproduction in any medium, provided the original author and source are credited.

Source of Support: Nil, Conflict of Interest: None declared. 